DEPARTAMENTO DE PATOLOGIA E CliniCA MEDICAS (2, CADEIRA)

Diretor: Pror. Dr. Paulo de Carvalho Pereira

\title{
VARIAÇŌES DOS TEÔRES PROTÉICOS DO SANGUE DE CAPRINOS DURANTE O DESENVOLVIMENTO ETARIO
}

\author{
(VARIATIONS ON THE PROTFIC LEVELS OF THE BLOOD OF GOATS
} DURING THE AGE DEVELOPMENT)

\author{
Fidcardo harry Birgel
}

Assistente Doutor

Em trabalhos anteriores, Birgel (1967), Birgel e Galvĩo (1968), Birgel e Araujo (1969) e Birgel (1969) estabelecem os teôres normais das proteínas sanguíners de capriros do sexo fominino, criados no Estado de São Paulo e fazendo estudo dos fatóres causadores de variação, afirmam as influências racias e almentares sôbre as proteinas sanguineas. Nos trabalhos citados, os autores apresentam vasta revisão bibliográfica, na qual se evidencia que poucas pesquisas se destinam a esclarecer a influência do fator etário sôbre o quadro protẻico de caprinos.

Falaschini e col. (1954), apresentam um estudo baseado no perfil electroforético de 15 caprinos durante seus seis primeiros meses de vida. Observam que no $20^{\circ}$ mês de vida, há diminuição do teôr de proteína total, seguidos de aumento gradativo, atingindo os valores máximos no quinto mês de vida. A distribuição das frações albumina decresce gradativamente com o aumento da idade, e conseqüentemente há aumento proporcional das globulinas.

BARBORIACK e col. (1958), estudando a constituiçāo protéica do sôro de fetos da espécie caprina, verificam que o mesmo difere do materno, pela presença de uma proteína especial, a "fetuina", e pela falta da fração gama globulina. O feto ao se desenvolver, apresenta incremento nos teôres de proteina total $e$ albumina, decréscimo na laxa de "fetuina" e manutenção dos níveis das frações alfa 1 , alfa 2 e beta globulinas.

GorCzyCA e MCCARTY (1959), Gorczyca e col. (1959) e GorcZYCA e col. (1960) afirmam a existência de influências de fatôres etários sôbre o fracionamento protéico do sôro sanguíneo de caprinos. Estes autores observam, que com o desenvolvimento etário 
há aumento dos teôres médios de proteina total, globulinas e gama globulinas com diminuição de valores de albumina e relação albumina globulinas.

\section{MATERIAL, E METOODOS}

Foram estudadas amostras sanguineas de 150 animais da espécic caprina (Capra hircus) do sexo feminino, clinicamente sadios, criados no Fstado de São Paulo. Formaram-se 5 grupos etários contendo cada um 30 animais assim organizados: o grupo etário I, constituido por cabritos cuja idade variava de nascimento até 6 meses de idade; o grupo etário II, composto por cabritos com ĩdade variando entre 7 e 12 meses de idade; o grupo etário III, com animais cuja idade variava entre 13 e 24 meses, grupo etário IV, constituido por caprinos com idades variando de 25 a 48 meses e, finalmente, grupo etário $\mathrm{V}$, constituido por animais de idade superior a 48 meses. Fistes grupos, formados por caprinos do sexo feminino eram homogêneos no que diz a respeito a raça, tipo de alimentaçāo, local e modo de criação.

As amostras de sangue for'am colhidłas por punção da veia jugular, usando-se agulhas $25 \times 12$, montadas $\mathrm{em}$ seringas segundo técnica usualmente empregadas. Visando evitar possivel hemólises, as agulhas e seringas foram prèviamente siliconizadas. Uma vez colhido o sangue, transferiamos $10 \mathrm{ml}$ da amostra para tubos onde ocorria a coagulação; após a retração do coágulo, o sôro cra separado por aspiração. O sangue destinado à dosagem de fibrinogênio era adicionado a uma solução $1,34 \mathrm{M}$ de oxalato de sódio, usando-se êsíc anticoagulante na proporção de $10^{\prime} \mathrm{i}$, sendo o plasma posteriormente separado por centrifugação.

As determinaçōes de protcina total, albumina, globulinas e cálculo da relação albumina globulinas no sôro foram feitas pelo método de Gorvall e col. (1949), fazendo-se a precipitação das globulinas com uma solução de sulfito de sódio a $27 \%$ ', como recomenda Birgel (1967).

As determinaçōes de gama globulinas no sôro for am feitas pelo método turbidimétrico de Frattini, como recomenda Baclla e col. (1962).

As determinaçōes de fibrinogênio no plasma foram feitas pelo método modificado de Cullen e Van Slyke, como preconiza QuICK (1959).

As verificaçōes da influência do desenvolvimento etảio sôbre o quadro protéico do sangue de caprinos foi testada pela análise da variância, de acôrdo com SNEDECOR (1956), não se considerando, respectivamente o teôr de globulinas e a relaçāo albumina globulinas, uma vez que tais valores não são independentes dos demais. 
O nivel de rejeição adotado para tôdas as comparaçōes foi de 1\%. O valor critico de F para 4 e 141 gráus de liberdade, respectivamente, para o tratamento e o residuo é 3,45 .

Foram calculadas as caracteristicas estatisticas para tôdas as provas realizadas, seguindo as recomendaçōes de GoMes (1963).

\section{RISULTADOS}

Na tabela I são apresentados os valores médios e amplitude de variação do teôr de proteina total obtido para os diferentes grupos etários dos caprinos estudados. Anexo à mesma é apresentado o valor de $F$ calculado na análise da variância.

TABELA I - Teôres de proteina total ( $\mathrm{g}$ por $100 \mathrm{ml}$ de sóro), nos diferentes grupor etários de caprínos do sexo feminino, criados no Estado de são Paulo. (Values obtained for total proteins (grams per $100 \mathrm{ml}$ of serum), In female goats, raised in the State of São Paulo, in acordance with age groups - in months.

\begin{tabular}{|c|c|c|c|c|c|c|c|}
\hline & \multirow[b]{2}{*}{ Grupo etário } & \multirow[b]{2}{*}{$\underset{\text { tra }}{\text { Amos- }}$} & \multicolumn{3}{|c|}{ Proteina total $\mathrm{g} \%$} & \multirow[b]{2}{*}{$\begin{array}{l}\text { Desvio } \\
\text { padrão } \\
\text { (s) }\end{array}$} & \multirow[b]{2}{*}{$\begin{array}{l}\text { Cocf. de } \\
\text { varlacũo } \\
\text { (C.V. \%) }\end{array}$} \\
\hline & & & $\begin{array}{l}\text { Valor } \\
\text { (m) }\end{array}$ & $\begin{array}{r}\text { médio } \\
\pm \quad s(\hat{m})\end{array}$ & $\begin{array}{l}\text { Amplitude } \\
\text { de varia- } \\
\text { cão A.V. }\end{array}$ & & \\
\hline I & até 6 meses & 30 & 5,78 & $\pm 0,094$ & $4,8-7,1$ & 0,504 & 8,72 \\
\hline II & 7 a 12 meses & 30 & 6,12 & $+0,128$ & $4,0-7,8$ & 0,692 & 11,31 \\
\hline III & 13 a 2.1 meses & 30 & 6,57 & $+0,122$ & $5,3-8,4$ & 0,657 & 10,00 \\
\hline & 25 a 48 meses & 30 & 6,80 & $\pm 0,159$ & $5,2-8,4$ & 0,859 & 12,63 \\
\hline $\mathrm{v}$ & mais de 48 meses & 30 & 6,91 & \pm 0.140 & $5,3-8,3$ & 0,754 & 10,91 \\
\hline \multicolumn{2}{|c|}{ Geral } & 150 & $6,44=$ & $\pm 0,067$ & $4,0-8,4$ & 0,822 & 12,76 \\
\hline
\end{tabular}

F $-45,86++$ (estatistlcamente significante ao nivel de rejelção de $1 \%$ ).

$\hat{\mathrm{m}}$ - valor médio (mean value)

$\mathrm{s}(\hat{\mathrm{m}})$ - desvio padrão da médla (mean standard desviation)

$s$ - desvio padrūo (standard desviation)

A.V. - Amplitude de varlaçao (variation from the data)

C.V. - Coeficiente de varlaçuo (Pearson's varlation coeficient).

$\mathrm{Na}$ tabela II são apresentados os valores médios e amplitude de variação do teôr de albumina obtidos para os diferentes grupos etários dos caprinos estudados. Anexo à mesma é apresentado o valor de $\mathrm{F}$ calculado na análise da variância.

Na tabela III e IV são apresentados os valores médios e amplitude de variação do teor de globulinas e da relação albumina/ globulinas obtidos para os diferentes grupos etários dos caprinos estudados.

Na tabela V são apresentados os valores médios e amplitude de variação do teôr de gama globulina obtido para os diferentes gru- 
pos etários de caprinos estudados. Anexo à mesma é apresentado o valor de $F$ calculado na análise da variância.

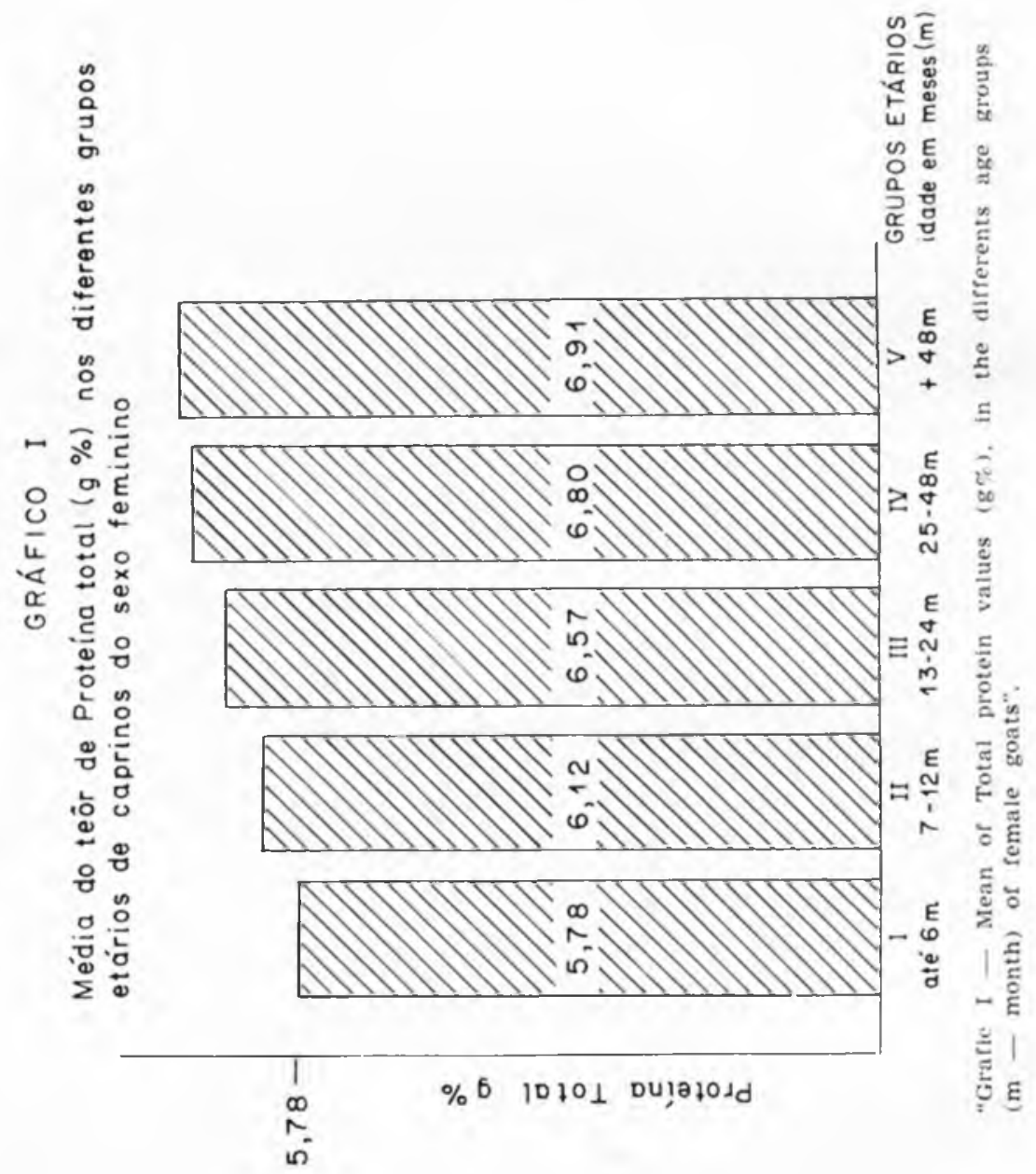

Na tabela VI são apresentados os valores médios e amplitude de variação do teôr de fibrinogenio obtido para os diferentes grupos etários dos caprinos estudados. Anexo à mesma é apresentado o valor de $\mathrm{F}$ calculado na análise da variância.

As variaçōes dos niveis protéicos durante o desenvolvimento etário são apresentados em histogramas, considerando-se sempre 
o valor mais elevado com igual a 100 e a partir dele calculamos por proporcionalidade a área dos demais grupos etários.

TABFisA II - Teôres de albumina ( $\mathrm{g}$ por $100 \mathrm{ml}$ de sôro), nos diferentes grupos etários de caprinos do sexo feminino, criados no Estado de São Paulo. (Values obatined for albumin (grams per $100 \mathrm{ml}$ of serum) in female goats, raised in the State of São Paulo, in acordance with age groups - in months.

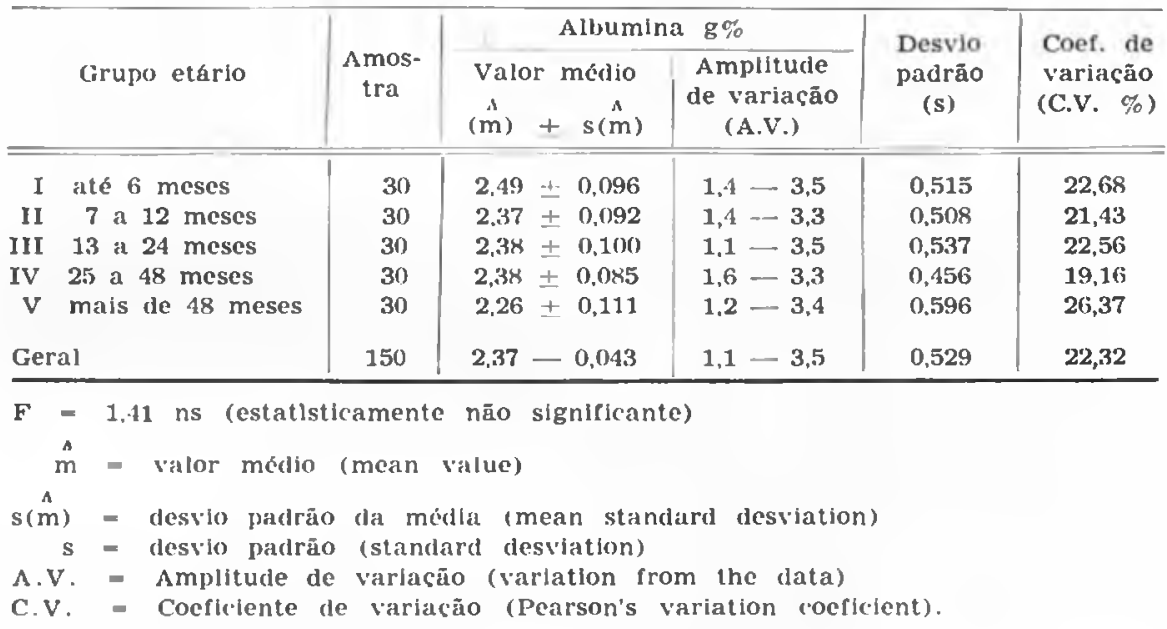

No gráfico I, apresentamos a média de proteína total, expressa em grama por $100 \mathrm{ml}$ de sôro, nos diferentes grupos etários de caprinos do sexo feminino.

No gráfico II, apresentamos a média de albumina, expressa em grama por $100 \mathrm{ml}$ de sôro, nos diferentes grupos etários de caprinos do sexo feminino.

No gráfico III, apresentamos a média de globulinas, expressa em grama por $100 \mathrm{ml}$ de sôro, nos diferentes grupos etários de caprinos do sexo feminino.

No gráfico IV, apresentamos a média do valor da relação albumina globulinas nos diferentes grupos etários de caprinos do sexo feminino.

No gráfico $\mathrm{V}$, apresentamos a média de gama globulina, expressá em grama por $100 \mathrm{ml}$ de sôro, nos diferentes grupos etários de caprinos do sexo feminino.

No gráfico VI, apresentamos a média de fibrinogênio, expressa em miligrama por $100 \mathrm{ml}$ de plasma, nos diferentes grupos etários de caprinos do sexo feminino. 


\section{GRÁFICO II}

Média do teör de Albumina $(g \%)$ nos diferentes grupos etários de caprinos do sexo feminino

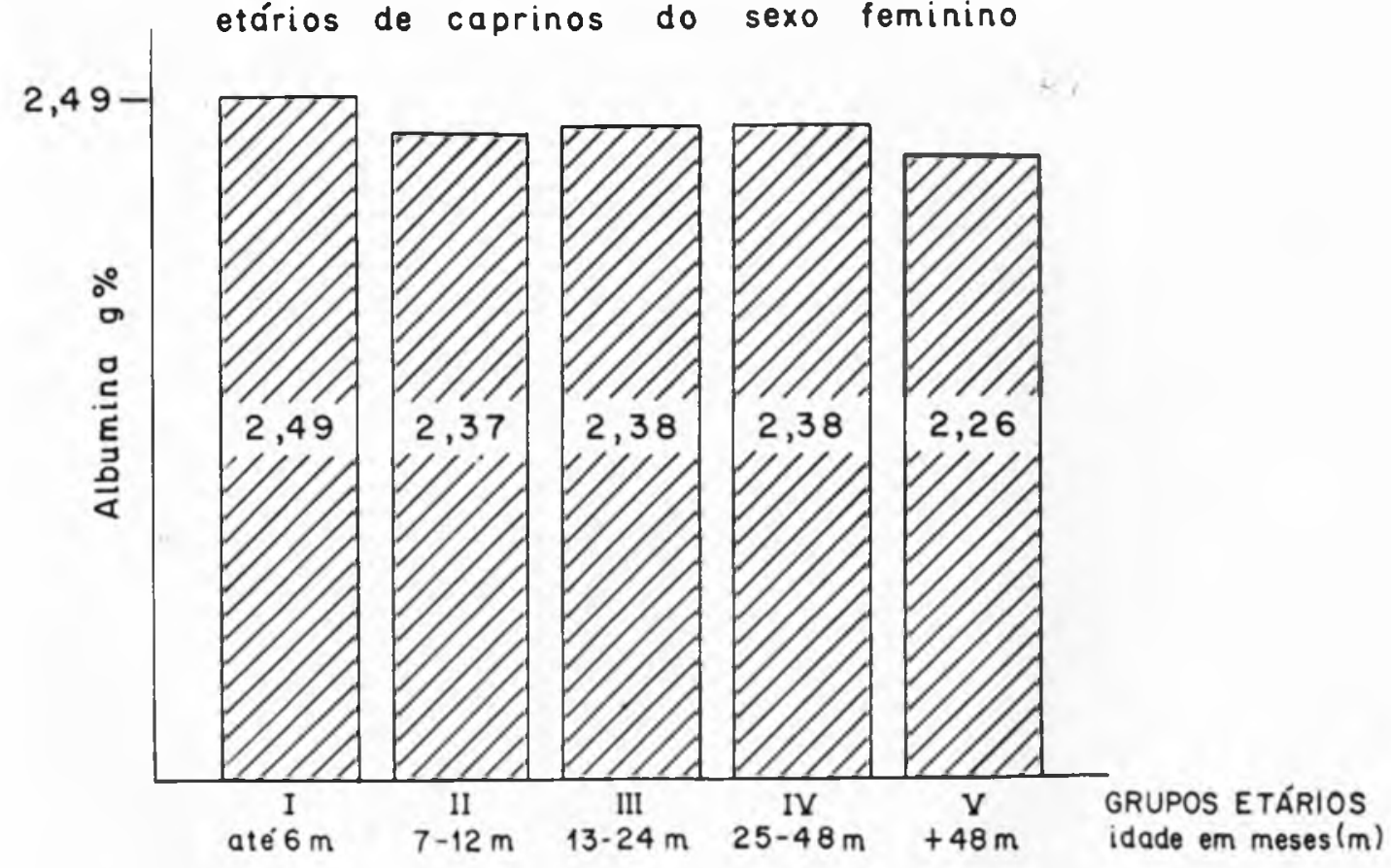

"Graflc II - Mean of Albumin values ( $\mathrm{g} \%$ ), in the differents age groups (m - month) of female goats". 
TABELA III - Teóres de globulinas ( $\mathrm{g}$ por $100 \mathrm{ml}$ de sôro), nos diferentes grupos etários de caprinos do sexo feminino, criados no Estado de São Paulo. (Values obtained for globulins (grams per $100 \mathrm{ml}$ of serum), in female goats, raised in the state of São Paulo, in acordance with age groups - in months.

\begin{tabular}{|c|c|c|c|c|c|c|}
\hline & \multirow[b]{2}{*}{ Grupo etário } & \multirow[b]{2}{*}{$\begin{array}{l}\text { Amos- } \\
\text { tra }\end{array}$} & \multicolumn{2}{|c|}{ Globulinas $\mathrm{g} \%$} & \multirow{2}{*}{$\begin{array}{l}\text { Desvio } \\
\text { padrão } \\
\text { (s) }\end{array}$} & \multirow[b]{2}{*}{$\begin{array}{l}\text { Cocf. de } \\
\text { varlacão } \\
\text { (C.V. \%o) }\end{array}$} \\
\hline & & & $\begin{array}{l}\text { Valor médio } \\
(\hat{m}) \pm s(\dot{m})\end{array}$ & $\begin{array}{l}\text { Amplitude } \\
\text { de variacião } \\
\text { (A.V.) }\end{array}$ & & \\
\hline I: & até 6 meses & 30 & $3,29+0.160$ & 2.0 a 4.9 & 0,862 & 26,20 \\
\hline II & 7 a 12 meses & 30 & $3,76 \pm 0.148$ & 1,8 a 5,4 & 0.798 & 21,22 \\
\hline III 1 & 13 a 24 meses & 30 & $4,19 \pm 0,170$ & 2.2 a 6,4 & 0,913 & 21,79 \\
\hline IV 2 & 25 a 48 meses & 30 & $4,45 \pm 0,210$ & 2,6 a 6,7 & 1.129 & 25,37 \\
\hline$v r$ & mais de 48 meses & 30 & $4,66 \pm 0,216$ & 2,5 a 6,8 & 1,163 & 24,96 \\
\hline \multicolumn{2}{|l|}{ Geral } & 150 & $4.07 \pm 0.090$ & 1.8 a 6.8 & 1,101 & 27,05 \\
\hline \multicolumn{7}{|c|}{$\hat{m}-$ valor médio (mean value) } \\
\hline \multicolumn{7}{|c|}{$\begin{array}{r}\hat{s}(\hat{m})=\text { desvio padrāo da média (mean standard desviation) } \\
s=\text { desvio padrão (standard desviation) }\end{array}$} \\
\hline \multirow{2}{*}{\multicolumn{7}{|c|}{$\begin{array}{l}\text { A.V. }=\text { Amplitude de } \\
\text { C.V. }\end{array}$}} \\
\hline & & le varla & ũo (l'carson's & bation coes & $n t)$. & \\
\hline
\end{tabular}

\section{GRÁFICO III}
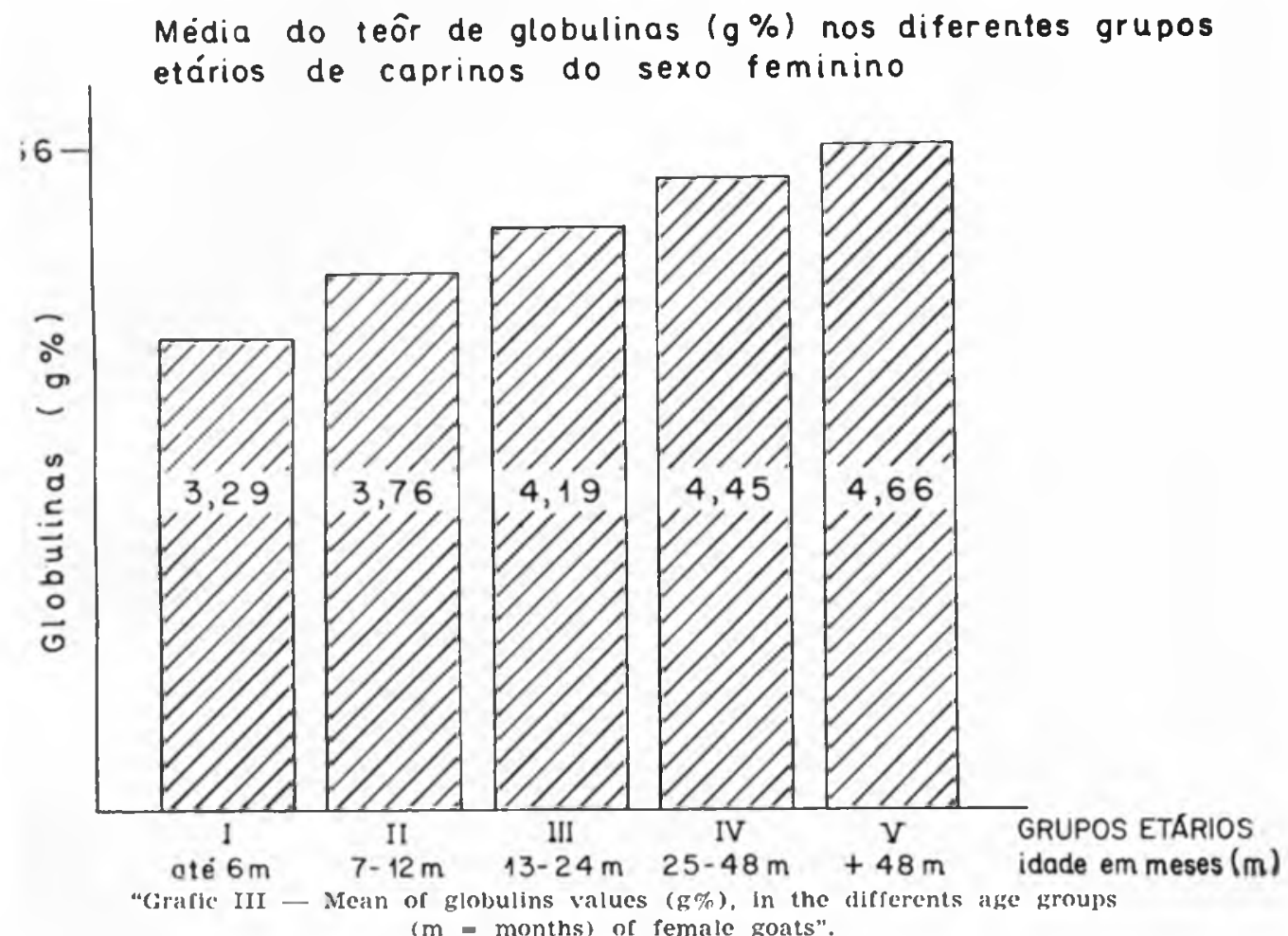
TABBI.A IV - Valores da relacão albumina/globulina, nos diferentes grupos etários de caprinos do sexo reminino. criados no kistado de Sio pitulo, ivalues of the albuminglobulins ratio. in female goats, raised in the state of sio Pato, in acordance with age groups - in months.

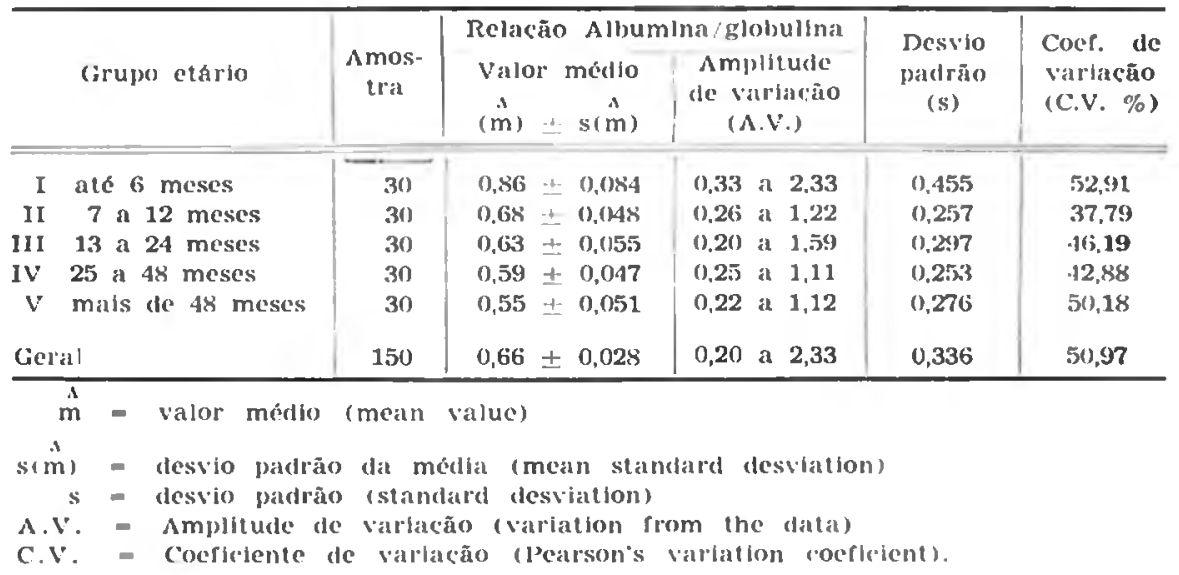

\section{GRÁFICO IV}

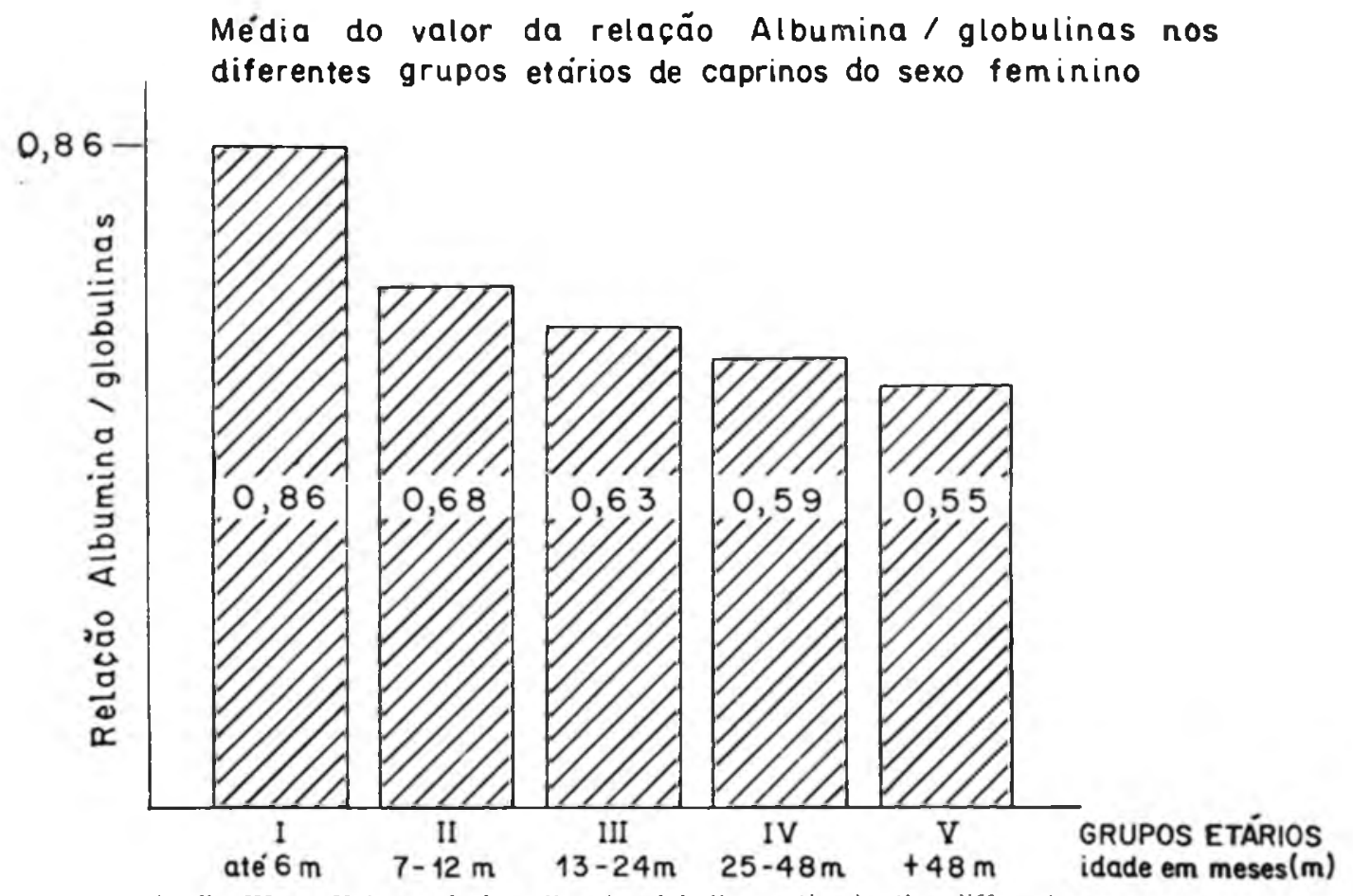

"Grafic: IV - Values of the albumin/globulins ratio, in the differents age sroups $(m=$ months $)$ of remale goats". 
TAlBEL A V - Teôres de gama globulinas ( $\mathrm{g}$ por $100 \mathrm{ml}$ de sòro), nos diferentes grupos etários de caprinos do sexo feminino, criados no Estado de São Paulo. (Values obtained for gama globulin (grams per $100 \mathrm{ml}$ of serum), in female goats, raised in the State of Sāo Paulo, in acordance with age groups - in months.

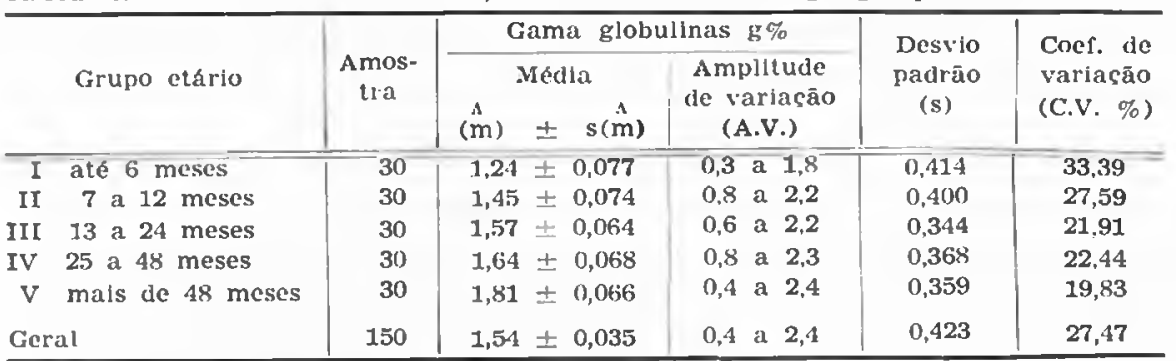

$\mathbf{F}-10,79++$ (estatisticamente significante ao nivel de rejelcāo de $1 \%$ ).

$\stackrel{1}{m}$

$\mathrm{s}(\hat{\mathrm{m}})$ - desvio padrão da médla (mean standard (lesviation)

s - desvio padrāo (standard desviation)

A.V. - Amplitude de variacão (variation from the data)

C.V. - Coefletente de variacũo (Pearson's variation coeficient).

\section{GRÁFICO V}

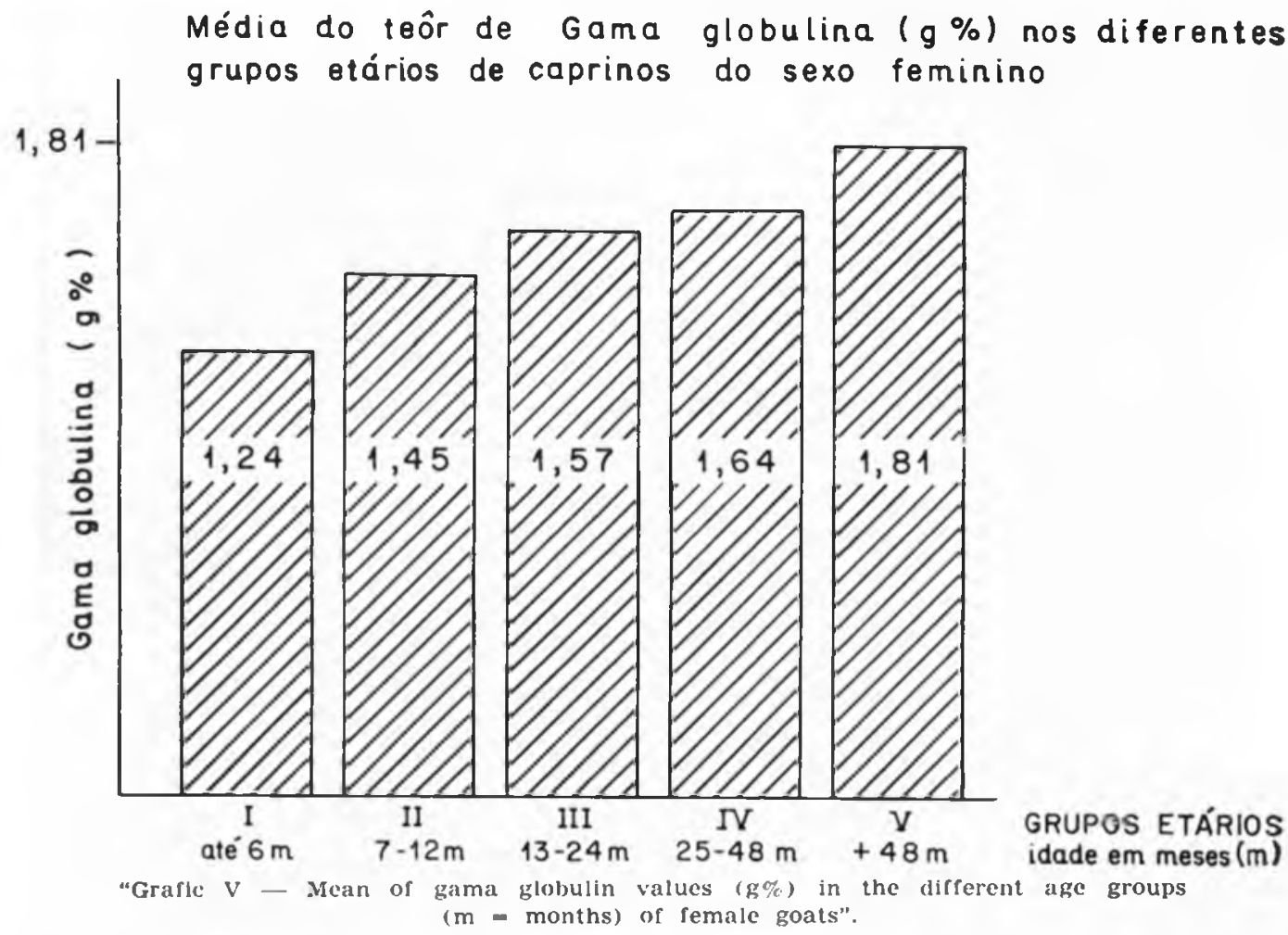


TABELA VI - Teōres de flbrinogênlo $(\mathrm{mg}$ por $100 \mathrm{ml}$ de plasma), nos diferentes grupos etários de (apminos (d) sexo feminino, criados no pstado de sủo paulo. (Values obtained for fibrinogen (mlligram per lok) $\mathrm{ml}$ of plasma), in female goats. raised in the state of sajo Paulo. in arordance with age groups - in months.

\begin{tabular}{|c|c|c|c|c|c|c|c|}
\hline & \multirow{3}{*}{ Grupo etário } & \multirow{3}{*}{$\underset{\text { trai }}{\text { Amos- }}$} & \multicolumn{3}{|c|}{ Fibrinogénlo mg\% } & \multirow{3}{*}{$\begin{array}{l}\text { Desilo } \\
\text { partrão } \\
\text { (s) }\end{array}$} & \multirow{3}{*}{$\begin{array}{l}\text { Cocf. de } \\
\text { variacioso } \\
\text { (C.V. (0) }\end{array}$} \\
\hline & & & \multicolumn{2}{|c|}{ Médla } & \multirow{2}{*}{$\begin{array}{l}\text { Ampliturle } \\
\text { de variacuāo } \\
\text { (A.V.) }\end{array}$} & & \\
\hline & & & (m) & $\pm s(m)$ & & & \\
\hline$I$ & ate 6 meses & 30 & 411.1 & 21,80 & 250 a 839 & 118.39 & 28.80 \\
\hline II & 7 a 12 meses & 30 & $3 \times 7.3$ & $\pm 18,65$ & $26 \mathrm{~s}$ al 6996 & 100,45 & 25.9 .9 \\
\hline III & $1: 3$ a 24 meses & 30 & $43 \cdot 1,9$ & \pm 21.99 & 155 is 696 & 118,44 & 27.23 \\
\hline IV & 25 at 48 meses & 30 & 426.7 & $\pm 25,05$ & 2337 a 759 & 134,90 & 31.61 \\
\hline v & mals de 48 meses & 30 & 454,3 & -32.46 & $17 x$ a $\mathrm{KSO}$ & $17-1.79$ & 38.47 \\
\hline \multicolumn{2}{|c|}{ Geral } & 150 & 423,3 & $\pm 10,95$ & 155 a $\$ 90$ & 133,69 & $31.5 \mathrm{~s}$ \\
\hline
\end{tabular}

F $=1.39$ ns (estatisticamente não signlficante).

$\stackrel{i}{\mathrm{~m}}=$ valor medlo (mean value)

$s(m)$ - desvio padrão da média (mean standard desviation)

$s$ - descilo padrão (standard desilation)

A.V. - Amplitude de variacão (variation from the data)

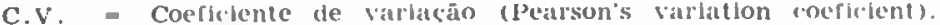

\section{GRÁFICO VI}

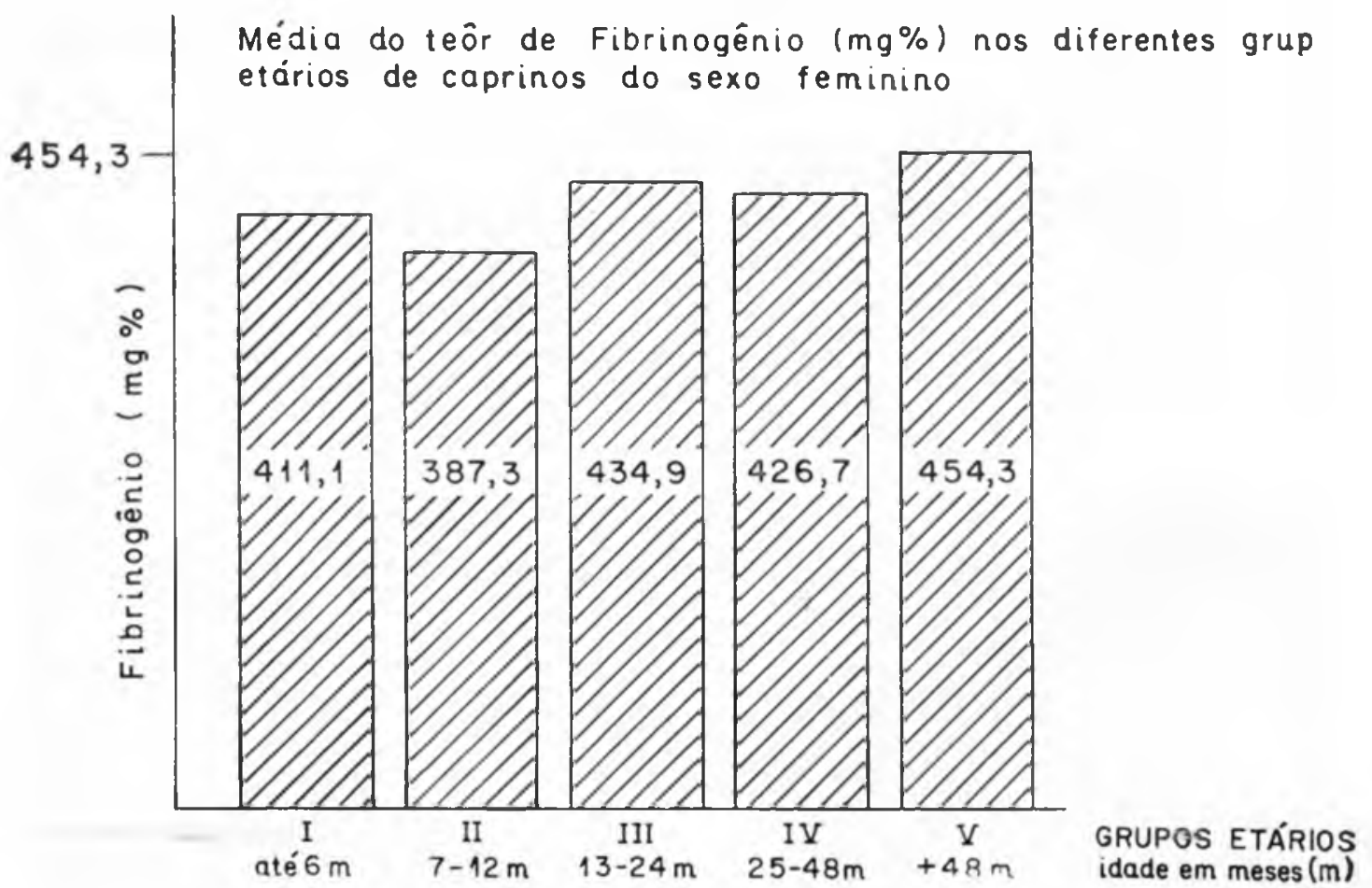

"Grafic VI - Mean of fibrinogen values (mg\%). In the different age groups

$(\mathrm{m}$ - months) of female goats". 


\section{DISCUSSก̃O}

Para os teôres de proteína total, verificamos haver variaçōes atribuiveis ao desenvolvimento etário, estatisticamente significantes ao nivel de rejeição de $1 \%$, havendo interação de fatôres etários, raciais e alimentares.

Encontramos para os grupos etários I, II, III, IV e V, respectivamente, os seguintes valores médios em grama por cento \pm desvio padrāo: $5,78 \pm 0,504 ; 6,12 \pm 0,692 ; 6,57 \pm 0,657 ; 6,80 \pm 0,859$ c 6,91 $\pm 0,754$. Analisando estas médias observamos que o teôr da proteina total aumenta gradativamente com a idade, sem haver estabilização do teôr protéico sérico, porém com o avançar da idade há diminuição sensivel da diferença entre a média dos grupos etários. As variaçōes observadas se referem mais aos teôres de globulinas e não de albumina, pois êstes ültimos como veremos adiante, não sofreram influência de fatôres etários. F̂stes fatos podem, ser examinados perfeitamente na tabela I e gráfico I.

Dos autores citados na revisāo bibliográfica mencionada, apenas Falaschini e col. (1954) e Gorczyca e MCCarty (1959) e GorCZYCA e col. (1959) e 1960) procuraram estudar as influências do fator etário, mas suas pesquisas se baseiam em amostras pequenas, sem planejamento especifico para elucidar a ação dêstes fatôres. Assim, Falaschini e col. (1954) verificaram teôres de proteina 1otal maiores em animais mais idosos. O resultado assemelha-se ao nosso, porém éstes autores se basciam apenas nos 6 primeiros meses de vida, os obtidos no primeiro mês $(5,78 \mathrm{~g} \%$ ) se comparam aos encontrados por nós no grupo etário I ( 0 a 6 meses de idade $5,78 \pm 0,504 \mathrm{~g} / \mathrm{c})$. Assinalam, para os caprinos aos 6 meses de idade, valores maiores $\left(8,45 \mathrm{~g}^{\prime} / \mathrm{c}\right)$, superiores a qualquer resultado obtido no presente trabalho.

GoRCZYCA e col. (1959) e GoRCZYCA e col. (1960) verificaram variaçōes devidas aos fatôres elários, pois em 10 caprinos fêmeas jovens e 14 adultas, encontram respectivamente os seguintes valores médios para proteina total: $6,30 \mathrm{~g}$ / $\mathrm{r}$ e $6,80 \mathrm{~g} \%$. Estes valores concordam com os nossos, pois assinalamos para animais de idade equivalente (grupos etários II e IV) respectivamente 6,12 $\pm 0,692$ e $6,80 \pm 0,859 \mathrm{~g} / \mathrm{c}$. Mas nos resultados obtidos pelos autores citados a variação etária é devida a diminuição de albumina e aumento de globulinas nos animais mais velhos, na presente pesquisa esta variação resulta exclusivamente do aumento das globulinas. Estes autores consideram que os caprinos adultos, entre 24 e 30 meses de idade, apresentam estabilidade do quadro protéico sanguineo, fato não obscrvado por nós.

BARBoriak e col. (1958), estudaram as variações do teôr de proteina total no sôro de fetos da espécie caprina durante sua evo- 
lução, evidenciando fato idêntico aquêle que ocorrre após o nascimento, isto é, aumento desstes valores com a evoluçāo dos fetos, e que se deve ao aumento da fração albumina, mantendo-se estável o teôr de globulinas.

Na análise de variância realizada para os valores de albumina, nāo assinalamos diferenças significantes atribuiveis ao fator etário. Encontramos para os grupos etários I, II, III, IV e V, respectivamente, os seguintes valores médios de albumina sérica \pm desvio padrão: $2,49 \pm 0,515 \mathrm{~g} \%, 2,37 \pm 0,508 \mathrm{~g} \%, 2,38 \pm 0,537 \mathrm{~g} \%$, $2,38 \pm 0,456 \mathrm{~g} \%$ e $2,26 \pm 0,596 \mathrm{~g} \%$. Pelo estudo destas médias, observa-se que o teôr de albumina, inicialmente diminui para se estabilizar entre 7 e 48 meses voltando a diminuir após êste periodo. Se o teôr de proteína total aumentou com o evoluir da idade, ocorrendo o inverso com os valores de albumina, somos obrigados a aceitar que a variação do teôr de proteina total se deve exclusivamente às globulinas.

Os resultados obtidos por FALASCHINi e col. (1954), discordam dos observados por nós, pois no primeiro semestre de vida, assinalam aumento da taxa de albumina.

GorCZyCA e col. (1959) e Gorczycu e col. (1960), verificaram que os caprinos mais velhos apresentam teôr de albumina menor que os jovens. Éstes resultados discordam dos nossos, porque êles trabalharam com grupos etários limitados, isto é, cujas idades variavam entre 7 a 9 meses e 24 a 30 meses, e, nesta faixa etária ( 7 a 48 meses) verificamos a estabilidade da taxa de albumina sérica. Talvez esta diferença seja devida a fatôres alimentares nāo mencionados por êstes autores.

No desenvolvimento fetal, BARBORIAK e col. (1958), observaram fato inverso do que ocorre após o nascimento, isto é, aumento do teôr de albumina sérica.

Os valores de globulinas séricas dos 150 caprinos que compōem nosso experimento, nāo puderam ser analisados estatisticamente, porque são dependentes do teôr de proteina total e albumina. As diferenças encontradas entre os grupos etários são evidentes, como pode ser observado na tabela III e gráfico III, e, jả salientamos anteriormente serem as variaçōes da proteina total sérica atribuiveis a êste fator, devidas exclusivamente à fração globulinica. Os resultados para os grupos etários I, II, III, IV e V, foram respectivamente os seguintes valores médios \pm desvio padrão: $3,29 \pm 0,862$ $\mathrm{g}^{\prime} / \mathrm{c}, 3,76 \pm 0,798 \mathrm{~g} \%, 4,19 \pm 0,913 \mathrm{~g} \%, 4,45 \pm 1,129 \mathrm{~g} \%$ e 4,66士 $1,163 \mathrm{~g} \%$. Nossos resultados são idênticos aos observados por FaLASCHINi e col. (1954) e GorCzyCa e col. (1959 e 1960).

Por motivos semelhantes aos mencionados para globulinas, a relação albumina globulinas nāo pode ser analisada sob aspectos 
estatísticos. Pela simples verificação dos resultados médios desta relação na tabela IV e gráfico IV notamos que a relação albumina globulinas, sofre variações devidas ao fator etário, decrescendo gradativamente com o aumento da idade, estabilizando-se após 1 ano de idade. Esta variação deve-se ao aumento do teôr de globulinas, mantendo-se mais ou menos constante a taxa de albumina. Nossos resultados concordam com aquêles calculados a partir dos teôres de albumina e globulinas citados por Falaschini e col. (1954) e GorCzyCA e col. (1959) e Gorczyca e col. (1960).

$\mathrm{Na}$ análise da variância efetuada com os valores de gama globulina, evidenciamos estatisticamente diferenças que sāo atribuídas ao fator etário, como podemos observar na tabela $\mathrm{V}$ e gráfico V. Encontramos para os grupos etários I, II, III, IV e V, respectivamente, os seguintes valores médios em gramas por cento \pm desvio padrão: $1,24 \pm 0,444,1,45 \pm 0,400,1,57 \pm 0,344,1,64 \pm 0,368$ e $1,81 \pm 0,359$. Analisando estas médias, podemos dizer, que o teôr de gama globulina aumenta gradativamente com a idade, sem haver sinais evidentes de estabilizaçāo desta fraçāo protéica, refutando mais uma vez a afirmaçāo de GorCZYCA e col. (1960), que consideram as cabras entre 24 e 30 meses de idade, amostras representativas da espécie e que a maturidade produz a estabilidade de concentração das proteinas sanguineas.

Nossos resultados concordam numèricamente, de forma mais acentuada com os observados por GorczYCA e col. (1960) e menos com os de FALASCHINI e col. (1954), mas ambos autores evidenciam niveis de gama globulina mais elevados para os animais mais idosos.

Em nossa pesquisa não se observaram variações significantes no teôr de fibrinogênio devidas à idade, porém de maneira geral os resultados nos animais jovens são menores que os obtidos em caprinos velhos. A literatura, não se refere a experimentos em que são feitos estudos referentes à influência da idade sôbre o teõr desta proteína no plasma de animais da espécie caprina. Porém em bovinos, Locatelli e QuARENGHi (1957), MinocCHERI (1961), BERETTA e LOCATELLI (1962), encontraram valores de fibrinogênio maiores em animais adultos que em fetos ou bezerros, portanto resultados similares aos observados por nós.

Resultados opostos aos citados foram obtidos por KoLB e Muller (1959), isto é, o teôr de fibrinogênio em bezerros foi maior que o encontrado em animais adultos.

Os resultados obtidos para as diferentes frações protéicas do sangue de caprinos do sexo feminino e às comparaçōes efetuadas entre os diferentes grupos etários, ao nível de rejeição de $1 \%$, permitem concluir que o quadro protéico de caprinos do sexo femini- 
no pretencente a várias raças, alimentados exclusivamente com forragens ou recebendo suplementação de ração concentrada, sofre influência de fatôres etários. A idade determina variaçōes estatisticamente significantes sôbre os teôres de PROTEÎNA TOTAL e GAMA GLOBULINA, sendo os mesmos menores nos animais mais novos. A variação na taxa de PROTEINA TOTAL se deve exclusivamente às GLOBULINAS. Em conseqüência das variaçōes verificadas nas fraçōes protẻicas do sôro, a relação $A L B U M I N A$ / GLOBULINAS foi relativamente maior nos grupos etários mais jovens.

A influência do fator etário sôbre o teôr de FIBRINOGENIO plasmático em caprinos não foi estatisticamente significante, apesar de se encontrar valores menores nos animais jovens.

As estimativas dos valores populacionais médios em têrmos de desvio padrão da média foram:

\begin{tabular}{|c|c|}
\hline Proteina total & $6,44 \pm 0,067 \mathrm{~g} / \mathrm{r}$ \\
\hline Albumina & $2,37 \pm 0,043 \mathrm{~g} / \mathrm{r}$ \\
\hline Globulinas & $4,07 \pm 0,090 \mathrm{~g}^{\prime}$ \\
\hline Gama globulinas & $1,54 \pm 0,035 \mathrm{~g} / \mathrm{c}$ \\
\hline Fibrinogê & $423,3 \pm 10,95 \mathrm{mg} / \%$ \\
\hline Relaçāo a & $0,66 \pm 0,028$ \\
\hline
\end{tabular}

SL:MMARY

In the following research the authors endeavours to establish the normal blood protein picture in goats (Capra hircus) raised in the State of São Paulo (Brazil).

This planning allows studying the influences of the age factor regarding the proteins constitution of the serum and the plasma in the animals of this species. Once the proteic picture is estabilished for the definite population which, through its distribution should be considered as a standard group, will serve as the basis for comparing the results obtained with animals presenting any affection, infestation or infection.

The authors studied 150 healthy female goats (Capra hircus) of different ages, raised in several areas of the State of São Paulo (Brazil), their breedings were Anglo-Nubian (60), Toggenbourg (60) and Angora (30).

For the purpose of studying any possible influence of age on the groups, each picture, the 150 goats were devided into 5 different age grooups, each one comprised of 30 animals; GROUP I, comprised of 6 months old goats; GROUP II, of goats with ages ranging from 7 to 12 months; GROUP III, comprised of goats with ages ranging from 
13 to 24 months; GROUP IV, with animals from 25 to 48 months and finally GROUP $V$, which was comprised of animals over 48 months old.

The author used the Gornall and col. (1949) method to determine the total protein, albumin, globulin and ratio of albumin/globulin in the serum. The original method was modified by precipitanting the globulins in a $27 \mathrm{~g} \%$ sodium sulfite solution.

The determination of the gama globulin in the serum was followed by the FRATTINI turbidimetric method, as recomended by BACILA and col. (1962).

The determination of fibrinogen in the plasma was reached by means the CULLEN and Van SLYKE modified method, as recomended by QUICK (1959).

In the tables I to VI, there are shown the proteic picture of the goats surveyed, separeted in acordance with age. The results are also present in an histogram form.

The results obtained for the different blood proteic fractions of female goats and for the comparison made among the different age groups, were tested at the $1 \%$ rejection level. Such results permitted the following conclusions.

The proteic picture for the female goats belonging to several breeds, fed exclusively on forrage or receiving additional concentrated feed was affected by age factors. The age determines a statisticaly significant variation over the TOTAL PROTEIN and GAMA GLOBULIN ratio, which is lower in the younger animals. This variation in the TOTAL PROTEIN rate is exclusively due to the GLOBULINS. As a consequence of the variations observed in the serum proteic fractions, the ALBUMIN GLOBULINS ratio was relatively higher in the younger group of animals.

The ages factor influences over the plasmatic FIBRINOGEN ratio in female goats was not statistically significant, in spite of there having been lower values in the younger animals.

The estimated mean values of all animals in relation to the mean standard deviation were.

\begin{tabular}{|c|c|}
\hline Total protein & $6,44 \pm 0.067 \mathrm{~g} \%$ \\
\hline Albumin & $2.37 \pm 0.043 \mathrm{~g} \%$ \\
\hline Globulins & $4.07 \pm 0.090 \mathrm{~g} \%$ \\
\hline Gama globulin & $1.54 \pm 0.035 \mathrm{~g} \%$ \\
\hline in & $\pm 10.95 \mathrm{mg} \%$ \\
\hline albumin/globulin & $0.66 \pm 0.028$ \\
\hline
\end{tabular}




\section{RFFFRENCIAS BIBLIOGRAFICAS}

1. BACILA, M. e col. - Técnicas atualizadas de bioquimica clinica. Curitiba, Conselho de Pesquisas da Universidade do Paraná, 1962.

2. BARBORIAK, J. J.; MESChIA, G.; BARRON, D. H. \& D. H. COWGILL, G. R. - Blood plasma proteins in fetal goats and checp. Pror. Soc'. exp. Biol. (N. Y.), 98:635-637, 1958.

3. BERETTA, C. \& LOCATFLLI, A. - Fibrinogeno e protrombina nel plasma di feto bovine. Clin. vet. (Milano) $85(7): 345-350,1962$.

4. BIRGF.L, E. H. - Contribuiçāo à hemotologia de caprinos (Capru hir(us), criados no Fstado de São Paulo. Determinaçōes dos teôres de proteinas séricas e plasmáticas em cabras normais. Influências de fatôres raciais, alimentares e etários. Tese apresentada a Faculdade de Medicina Veterinária da U.S.P. para obtençāo do titulo de mestre, 1967.

5. BIRGFL, F. H. \& ARAUJO, I. M. - Quadro protêico de fémeas da espécie caprina (Cupre hircus) criados no Estado de São Paulo. Rer. Fuc. Med. Vet. (São Paulo), z(4):953-969, 1968.

6. BIRGEL, E. H. \& GALVAO, M. C, G. - Consideraçōes sôbre o teôr de fibrinogênio no plasma de fêmeas da espécic caprina (Cupru hircus). Estudo dos fatores de variabilidade. Arq. Inst. Biol. (São Paulo) 85 (4) :165-172, 1968.

7. BIRGEL, E. H. - Influências de fatōres raciais c alimentares sỏbre o quadro protêico do sangue de caprinos. Rev. Fúc. Med. Vet. (São Paulo), 8(1): $\quad$, 1969

8. FALASCIIINI, A.; BIONDO, G. \& LEONTI, F. - Dificazioni della protidemia nei caprini in rapporto all'etá ed al regime alimentare. Atti. Soc. itul. Sci. vet., 8:388-391, 1954.

9. GOMES, F. P. - Curso de estatística. Piracicaba, Ediçōes Didáticas, 1963.

10. GORCZYCA, L. R. \& MCCARTY, R. T. - Changes in serum proteins of goats produced by momiliasis infection. Vet. Med. 54:373-376, $1959 \mathrm{a}$.

11. GORCZYCA, L. R.; McCARTY, R. T. \& LIMON, J. M. - Studies of goats scrum proteins by paper electrophoresis. Amer. J. ret. Res., 20 (78) :921-924, $1959 \mathrm{~b}$.

12. GORCZYCA, L. R.; McCARTY, R. T. \& LAZARONI, J. A. Jr. - Further studies of goat serum proteins by paper electrophoresis. Amer. $J$. vet. Res., $21: 851-855,1960$.

13. GORNALL, A. G.; BARDAWILL, C. J. \& DAVID, M. M. - Determination of serum proteins by means of the biuret reactions. $J$. biol. Chem., 11\%:751-761, 1949.

14. KOLB, E. \& MULLER, A. - Zum vorkommer und zur Bestimmung des Fibrinogens in Plasma vom Ilautieren. Zbl. Vet. Med., 6:14-27, 1959. 
15. LOCATELLI, A. \& QUARENGHI, F. - Valori di fibrinogeno nel vitello neonato. Atti. Sor. ital. Sri. Vet., 10:286-289, 1956.

16. MINOCCHFRI, F. - Comportamento quantitativo e qualitativo del fibrinogenio di alcune specie animali studiato medianti turbidimetria e microclectroforesi su gel di agar. Arch. vet. ital., 12(5):385-392, 1961.

17. QUICK, A. J. - Hemorragic diseases. Philadelphia, Lea e Febiger, 1959.

18. SNEDECOR, G. W. - Statistical methods. Aplied to experimenths in agriculture and biology. $5^{1 / 1}$ ed. Iowa, State College Press, 1956. 